\title{
Adolescent Changes in the Homeostatic and Circadian Regulation of Sleep
}

\author{
M.H. Hagenauer a, b J.I. Perryman ${ }^{\text {a }}$ T.M. Lee ${ }^{\text {a-c }}$ M.A. Carskadon ${ }^{\text {d, } e}$ \\ a Neuroscience Program, ${ }^{b}$ Reproductive Sciences Program, and ${ }^{\mathrm{C} D e p a r t m e n t ~ o f ~ P s y c h o l o g y, ~ U n i v e r s i t y ~ o f ~ M i c h i g a n, ~}$ \\ Ann Arbor, Mich., d Department of Psychiatry and Human Behavior, Alpert Medical School of Brown University, \\ Providence, R.I., and 'Sleep and Chronobiology Laboratory, E.P. Bradley Hospital, East Providence, R.I., USA
}

\section{Key Words}

Puberty $\cdot$ Chronotype $\cdot$ Entrainment $\cdot$ Sleep deprivation

\begin{abstract}
Sleep deprivation among adolescents is epidemic. We argue that this sleep deprivation is due in part to pubertal changes in the homeostatic and circadian regulation of sleep. These changes promote a delayed sleep phase that is exacerbated by evening light exposure and incompatible with aspects of modern society, notably early school start times. In this review of human and animal literature, we demonstrate that delayed sleep phase during puberty is likely a common phenomenon in mammals, not specific to human adolescents, and we provide insight into the mechanisms underlying this phenomenon.

Copyright $\odot 2009$ S. Karger AG, Basel
\end{abstract}

\section{Overview of Adolescent Sleep Patterns in Humans}

A recent poll by the National Sleep Foundation found that over $45 \%$ of adolescents in the United States obtain inadequate sleep [1]. At the root of this chronic sleep deprivation is the adolescent tendency to stay up late. Teenagers maintain later bedtimes than younger adolescents, even when wake up times are constrained by school or work [2-6]. This delayed timing of sleep is popularly attributed to many external influences, ranging from evening work to social opportunities [7]. Current evidence demonstrates, however, that social factors cannot completely account for the adolescent delayed sleep onset typical of an evening chronotype.

The developmental timing of the adolescent transition into a more evening chronotype suggests physiological underpinnings. Girls begin to show a delay in the timing of sleep 1 year earlier than boys, paralleling their younger pubertal onset. Maximum delay also occurs earlier in girls (19.5 vs. 20.9 years), and the magnitude of the peak delay is sexually differentiated [5]. In other cultures, similar developmental timing is observed, although the peak delay may occur as early as 15-16 years of age [1-6]. Importantly, a delay in the timing of sleep during the second decade of life has been observed in over 16 countries on 6 continents, in cultures ranging from pre-industrial to modern (as reviewed in [8]). Although most studies have been cross-sectional, retrospective longitudinal measures confirm that the timing of sleep is delayed during adolescence [5].

Adolescents continue to show a delayed circadian (or internal clock) phase as indicated by daily endocrine rhythms even after several weeks of regulated schedules that allow for sufficient sleep. This delay is maintained under controlled laboratory conditions in which there is

\section{KARGER}

(ㄷ) 2009 S. Karger AG, Basel

Fax +41613061234

E-Mail karger@karger.ch

www.karger.com
Accessible online at:

www.karger.com/dne
Megan Hagenauer

Department of Psychology

530 Church St.

Ann Arbor, MI 48109-1043 (USA)

Tel. +1 734709 7204, Fax +1 734763 7480, E-Mail hagenaue@umich.edu 
Table 1. A delay in circadian phase has been observed around the time of puberty in six mammalian species

\begin{tabular}{|c|c|c|c|c|c|c|}
\hline & \multicolumn{6}{|l|}{ Species } \\
\hline & $\begin{array}{l}\text { human } \\
\text { (Homo sapiens) }\end{array}$ & $\begin{array}{l}\text { rhesus monkey } \\
\text { (Macaca mulatta) }\end{array}$ & $\begin{array}{l}\text { degu } \\
\text { (Octodon degus) }\end{array}$ & $\begin{array}{l}\text { laboratory rat } \\
\text { (Rattus norvegicus) }\end{array}$ & $\begin{array}{l}\text { laboratory mouse } \\
\text { (Mus musculus) }\end{array}$ & $\begin{array}{l}\text { fat sand rat } \\
\text { (Psammomys obesus) }\end{array}$ \\
\hline Magnitude of delay & $1-3 \mathrm{~h}$ & $2 \mathrm{~h}$ & $3-5 h$ & $1-4 \mathrm{~h}$ & $1 \mathrm{~h}$ ? & $\begin{array}{l}0-3 \text { h under a long } \\
\text { photoperiod }{ }^{*}, 10- \\
14 \text { h under a short } \\
\text { photoperiod }\end{array}$ \\
\hline Sex difference & males $>$ females & $\begin{array}{l}\text { only females } \\
\text { examined }\end{array}$ & males $>$ females & males $>$ females & $\begin{array}{l}\text { only females } \\
\text { examined }\end{array}$ & sex unspecified \\
\hline Rhythms delayed & sleep, melatonin & activity & activity, sleep? & activity & $\begin{array}{l}\text { activity, corticosterone, } \\
\text { temperature?*}\end{array}$ & $\begin{array}{l}\text { oxygen consumption, } \\
\text { temperature }\end{array}$ \\
\hline No. of experiments & $>20$ & 1 & 6 & 4 & 2 & 1 \\
\hline Age of peak delay & $15-21$ years & 39 months & 80-100 days & 30-40 days & $\begin{array}{l}\text { unknown, but delay } \\
\text { evident at } 35-45 \text { days }\end{array}$ & $\begin{array}{l}\text { unknown, but delay } \\
\text { evident at } 35-42 \text { days }\end{array}$ \\
\hline $\begin{array}{l}\text { Age of establishing } \\
\text { overt cyclicity in } \\
\text { females }\end{array}$ & $\begin{array}{l}\text { menarche: } \\
12-13 \text { years } \\
\text { regular ovulation: } \\
13-16 \text { years } \\
{[21]}\end{array}$ & $\begin{array}{l}\text { menarche: } \\
30-33 \text { months } \\
\text { first ovulation: } \\
42-45 \text { months } \\
{[12]}\end{array}$ & $\begin{array}{l}\text { cycles in vaginal } \\
\text { opening: } \\
35-150 \text { days } \\
{[13,16]}\end{array}$ & $\begin{array}{l}\text { first ovulation: } \\
35-45 \text { days } \\
{[22]}\end{array}$ & $\begin{array}{l}\text { first ovulation: } \\
27-40 \text { days } \\
\text { regular ovulation: } \\
30-80 \text { days } \\
{[23-24]}\end{array}$ & unknown \\
\hline $\begin{array}{l}\text { Age of establishing } \\
\text { spermatogenesis }\end{array}$ & $\begin{array}{l}12-16 \text { years } \\
{[21]}\end{array}$ & $\mathrm{n} / \mathrm{a}$ & $\begin{array}{l}60-120 \text { days } \\
{[13]}\end{array}$ & $\begin{array}{l}45-65 \text { days } \\
{[22]}\end{array}$ & $\mathrm{n} / \mathrm{a}$ & $\begin{array}{l}28-56 \text { days } \\
{[25]}\end{array}$ \\
\hline Gonadal dependent & maybe & unknown & maybe & maybe & unknown & unknown \\
\hline Circadian citations & reviewed in $[4,8]$ & {$[12]$} & {$[13-16]$} & {$[16-17]$} & {$[18-19]$} & {$[20]$} \\
\hline
\end{tabular}

* Not statistically significant.

limited possibility for social influence [7, 9]. Moreover, both home-based and laboratory studies of adolescents show that delayed circadian phase correlates with secondary-sex development $[7,10,11]$. This correlation holds true for subjective ratings of chronotype and puberty even when grade level in school is held constant [11]. If we assume that teenagers attending the same grade in school are exposed to a similar social environment, this evidence suggests that a biological component drives adolescent changes in sleep patterns.

\section{Animal Studies Demonstrate a Delayed Internal Clock during Puberty}

If physiologic processes drive adolescent sleep patterns, then we would expect that other mammalian species might show similar changes in the timing of sleep and activity around the development of sexual maturation. To test this hypothesis, we reviewed data from nine studies that examined the daily rhythms of mammals during pubertal development [12-20]. We inferred the timing of puberty by referencing universal markers (the initiation of spermatogenesis and ovulation) discussed in previously published reproductive studies for each species [21-25]. We defined puberty as the age interval between the first indication of secondary-sex development and the achievement of reproductive competency.

This review found evidence for delayed circadian phase during puberty in all five species studied: Macaca mulatta (rhesus macaque [12]), Octodon degus (degu [1316]), Rattus norvegicus (laboratory rat [16, 17]), Mus musculus (laboratory mouse $[18,19]$ ), and Psammomys obesus (fat sand rat [20]). Overall, this evidence indicated that the delayed timing of sleep during human adolescence is likely to represent a developmental change common across mammalian species (table 1).

Several themes emerged while comparing different species. The first concerned the magnitude of the phase delay: with the exception of fat sand rats maintained under short, winter-like photoperiods [20], all other species and all experimental conditions provided evidence for a 
1- to 4-hour delay in circadian rhythms during puberty. This phenomenon was replicable and observed independently by six different laboratories (table 1). The daily rhythms measured were diverse and included behavioral rhythms, such as sleep and activity, and physiological rhythms, such as endocrine and metabolic rhythms.

The magnitude of the delay in humans was sexually differentiated as seen for example in a large epidemiological study performed in Germany and Switzerland, where men showed greater changes in chronotype across adolescence and young adulthood than women [5]. Similarly, male degus and rats showed pronounced changes in the timing of peak activity across puberty, whereas females produced smaller changes in the timing of activity onset or offset [16]. These sex differences may be due to a sexual differentiation of the phenomenon itself or to a masking of the phenomenon by the estrogenic phase advance of rhythms around the time of ovulation [26].

The delay in several species was accompanied by an increase in crepuscularity, or activity around the transition times of dawn and dusk. In well-rested human subjects, adolescents showed a decreased propensity to fall asleep in the evening hours [27], as well as an increase in midday sleepiness as measured by the multiple-sleep latency test [28]. In the degu and rat, similar trends were observed. Pubertal degus showed less NREM sleep around the times of lights-on and lights-off than adult degus [15]. Also, in both degus and rats, as activity rhythms phase delayed during puberty, activity around the light-transition periods remained stable, leading to a bimodal activity distribution [16].

Most intriguing is the relationship between delayed phase and pubertal development. In the human literature, delayed circadian phase correlates with secondarysex development $[8,10,11]$. A study comparing the activity rhythms of rhesus macaques with normal or delayed pubertal development similarly reported a strong correlation between pubertal timing and circadian phase delay [12]. In humans, sex differences in the timing of pubertal commencement were reflected in the timing of circadian phase delay [5]. In pubertal rats, a correlation was found between sex differences in the timing of genital development and the timing of phase delay [16]. Preliminary analyses in degus have not revealed similar trends, but the sample size remains small [16].

In all species studied, circadian phase delay appeared to begin around the onset of puberty; however, the timing of peak phase delay during puberty occurred relatively later in humans than in other species (table 1). The peak phase delay in humans occurred either during or follow- ing the final stages of gonadal development. In all other species examined, peak phase delay appeared to take place in the middle of secondary sex development. The reason for this difference in developmental timing is unclear, but a role for artificial lighting in prolonging delayed phase in human adolescents is a possibility. With an ability to adjust our own light cycles, behavioral habits can lead to altered zeitgeber exposure and atypical circadian phase [29]. There is also growing evidence from imaging studies that several brain regions continue to develop in humans into the early twenties [30]. Therefore, it may be that these developmental differences arise because human brain development is more prolonged than that of rodents. Finally, the progression of sexual development in the other species studied is not completely analogous to that of humans. Many rodent species show low levels of steroidogenesis and secondary sex development throughout the juvenile period that accelerates near the development of reproductive competency [22]. This early steroid exposure may hasten developmental changes in circadian phase.

Several weaknesses in this comparative analysis need to be acknowledged. First, many of the studies were not intentionally designed to observe this phenomenon, and therefore they only measured circadian phase at 1 or 2 pubertal time points $[13,15,18-20]$. This inconsistency makes it difficult to estimate and compare the magnitude of developmental change across species or to verify that rhythms that did not show a significant developmental change were not missed by the sampling window (e.g. temperature rhythms in ref. [19]; or rhythms in melatonin synthesis and metabolism in ref. [20]). Second, many of these studies did not simultaneously monitor pubertal development [14, 17-20]. This is problematic because, for animals living in laboratories, lighting conditions during a circadian experiment can mimic seasonal changes in day length and alter pubertal progression [31].

Despite these weaknesses, this evidence still provides strong support for the hypothesis that a delay in circadian phase around the time of puberty is a common phenomenon across mammalian species. What is the mechanism underlying these changes?

\section{The Mechanism Underlying Adolescent Changes in Sleep Patterns}

Traditionally, the timing of sleep is thought to derive from two primary endogenous components: a circadian timing system and a homeostatic drive. The homeostatic 
drive for sleep, or sleep pressure, increases with the duration of waking and dissipates during sleep. In humans, the circadian timing system promotes wakefulness in the evening and promotes sleep in the early morning [32]. The Carskadon laboratory developed a theoretical model of delayed sleep phase during adolescence that incorporates developmental changes in homeostatic drive and circadian timing. According to this model, human adolescents develop a resistance to sleep pressure that permits them to stay up later. At the same time, their circadian phase becomes relatively delayed, which provides them with a drive to stay awake later in the evening and to sleep later in the morning [8].

Adolescent Changes in the Homeostatic Drive to Sleep Only a few cross-sectional studies have examined homeostatic sleep drive in adolescent humans. One study of extended wakefulness in early/pre- and postpubertal humans tested for sleep propensity at 2 -hour intervals. Data showed that the more mature adolescents are slower to fall asleep at critical times (after 14.5 and $16.5 \mathrm{~h}$ awake, i.e. in the late evening) relative to younger adolescents [27]. In another study, pre-pubertal adolescents were shown to have identical dissipation rates of sleep pressure across the night [33], yet the buildup of sleep pressure modeled as accumulation of slow-wave activity (SWA, a sleep electroencephalographic (EEG) marker of homeostatic drive) in response to sleep deprivation - was slower in postpubertal than prepubertal children [34]. These findings combine to indicate that more mature adolescents are able to tolerate somewhat longer waking episodes than pre-pubertal adolescents, though the similarity in dissipation rates indicates that the sleep recovery process is developmentally stable.

Very few studies have explored sleep pressure in animal models during puberty. Previous studies in young rats demonstrated that these animals have significantly increased homeostatic drive to sleep following either day or night deprivation protocols [35]. Following both deprivations, juvenile rats (23 and 29 days) experienced more NREM sleep, higher consolidation of sleep episodes and higher sleep intensity (as measured by NREM EEG delta power $(0.5-4.5 \mathrm{~Hz})$ or SWA) as compared to baseline and compared to adults [35-37]. The extent of the sleepdeprivation response dissipated across puberty, and by the age of midpuberty (40 days), young rats displayed decreased total amount of NREM sleep and delta power in baseline conditions and a more blunted homeostatic response to sleep deprivation relative to a younger age [35]. The homeostatic sleep response during puberty has also been measured in the diurnal rodent, Octodon degus. Like adults, male pubertal degus displayed a rhythmic homeostatic drive to sleep (increasing during the day and dissipating at night). In these pubertal degus, however, the increase in the intensity of NREM sleep (delta power) following a 6-hour night sleep deprivation was greater than that found in adult degus [15]. Delta power was also elevated for longer following a 6-hour deprivation in the 3-month-old pubertal animals than adults [15]. These data parallel human adolescent findings.

\section{Adolescent Changes in the Circadian Regulation of Sleep}

Growing evidence supports the conjecture that endogenous circadian period and light sensitivity of the circadian system are altered during puberty in humans and animals. Such changes could explain the development of delayed sleep phase during puberty.

Circadian rhythms in mammals are generated internally by a pacemaker in the suprachiasmatic nucleus (SCN) of the hypothalamus [38]. Therefore, under conditions in which there are no time cues from the outside world (also referred to as constant or free-running conditions), the circadian system continues to generate daily rhythms. The timing of these endogenously-generated rhythms drift a little each day, because the period $(\tau)$ of the rhythms only approximates $24 \mathrm{~h}$. Under normal conditions, the endogenous rhythm must be entrained (or synchronized) by external time cues (such as light) to maintain a stable phase relationship with the outside world. This entrainment can occur by two different mechanisms: discrete (or nonparametric) entrainment and continuous (or parametric) entrainment [39].

Discrete Entrainment. Corrects for the difference between the period $(\tau)$ of the circadian pacemaker and the 24 -hour day length of the external world by daily phase resetting $[39,40]$. To measure the circadian system's sensitivity to the discrete effects of light, researchers experimentally produce a behavioral phase-response curve (PRC). A photic PRC illustrates the magnitude of circadian phase shift in response to a brief light exposure that is presented at any particular circadian phase [40]. In general, light exposure during the subjective morning produces phase advances, whereas light exposure during the subjective evening produces phase delays [40].

Continuous Entrainment. Occurs when light exposure modifies $\tau$ so that it approaches the 24-hour day length without daily resetting [39]. Continuous mechanisms of entrainment are found in most species (although not well studied) and hypothesized to be especially important for 
the entrainment of diurnal mammals [41]. Since these effects are long-lasting, the aftereffects of photoperiod on $\tau$ can often be observed for days after transferring an animal into constant conditions [42].

If changes in circadian entrainment underlie pubertal changes in the circadian phase, then the magnitude of phase change should be sensitive to the quality and intensity of the synchronizing cue. This appears to be the case. Research from the fat sand rat indicates that a greater magnitude of phase change during development occurs under conditions of short photoperiod (shorter duration of light per day) than with long photoperiod [20]. Preliminary evidence from the degu also suggests that the magnitude of pubertal phase change is sensitive to lighting intensity [43]. What happens during puberty to produce a phase delay?

An elongated $\tau$ would cause the circadian pacemaker and its rhythmic output to delay relative to the light cycle [39] (fig. 1, model A). In support of this hypothesis, human adolescents have a $\tau$ of $24.27 \mathrm{~h}$, a period length significantly longer than that found in adults ( $24.12 \mathrm{~h}$ ) using similar protocols $[8,44]$. Longitudinal research to better test this hypothesis is currently underway in the Carskadon laboratory.

Data from rodents are inconsistent with this human finding. Pubertal $\tau$ in male rats was longer than the adult period [17]: however, later work suggests that this change may be sex-specific and unrelated to pubertal changes in phase [Possidente et al., unpubl. data]. Similarly, a careful developmental analysis of the degu did not find changes in $\tau$ during puberty at the age of the delay in entrained phase [13].

Enhanced Light-Elongation of $\tau$. This discrepancy between the results of human, rat, and degu studies might be explained by the presence or absence of light exposure during the free-running protocols. The pubertal rodents were exposed to constant darkness (DD, [13]) or very dim red light $(0.1 \mathrm{~lx}$ RR [17]) while $\tau$ was measured. Whereas humans were exposed to a light cycle (LD; 20 vs. 0 lx) with a day length $(\mathrm{T})$ that was outside of the range of entrainment for the circadian system $(\mathrm{T}=28 \mathrm{~h})$ [44]. Previous experiments have shown that light exposure can lengthen free-running period in five species that have pubertal phase delay [45-49]. Therefore, $\tau$ may not be longer during puberty, but the circadian pacemaker may be more sensitive to the continuous effects of light. In support of this hypothesis, aftereffects of photoperiod on $\tau$ are more prolonged in pubertal than adult rodents $[13,43]$.

Increased Sensitivity to the Phase-Delaying Effects of Light. An increase in the circadian pacemaker's sensitiv-

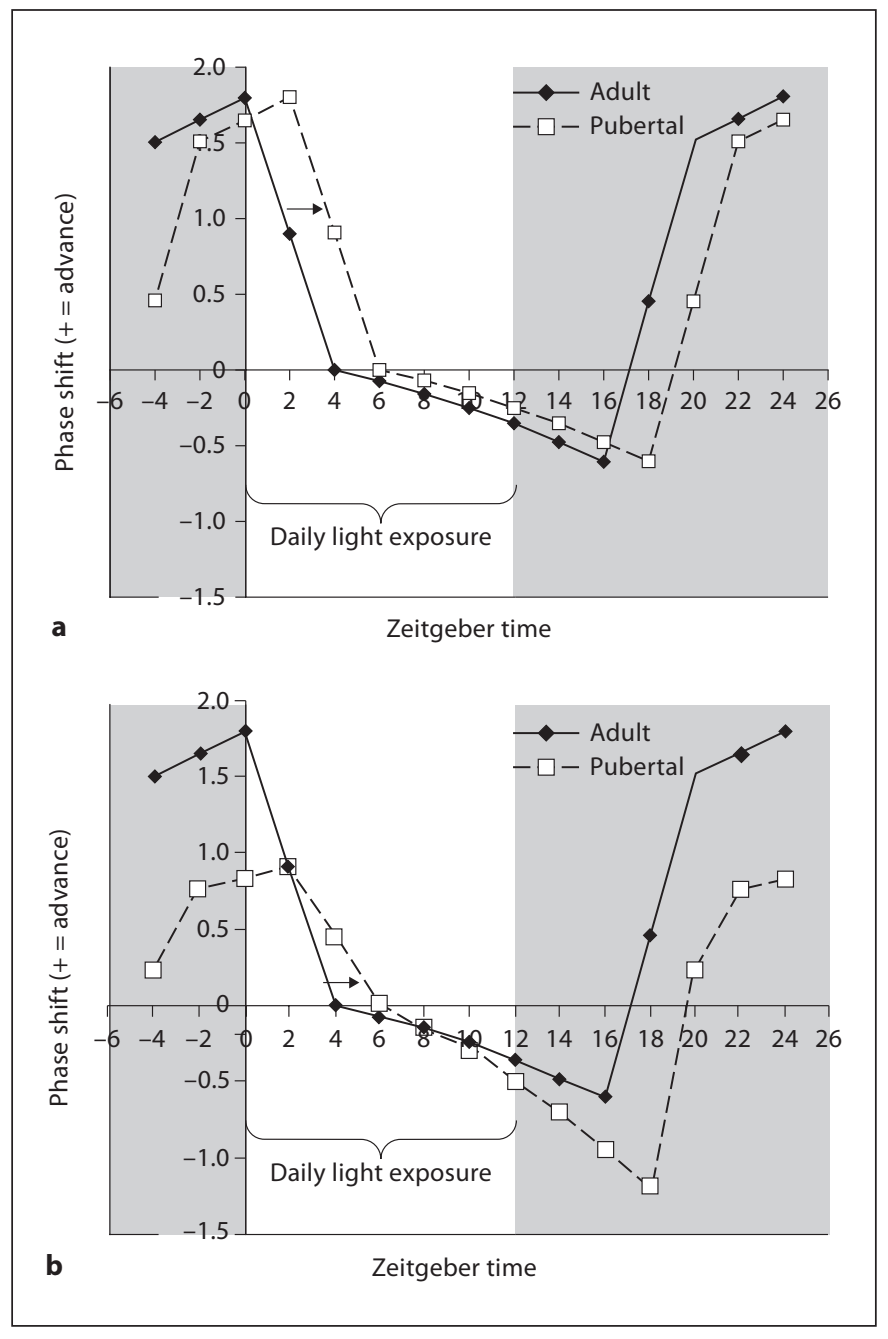

Fig. 1. Two potential mechanisms underlying delayed circadian phase during puberty. These mechanisms are illustrated using a PRC depicting the circadian phase response of male degus to a light pulse presented at different times of the day. Phase shift magnitude is graphed in hours, with positive values indicating phase advance, and negative values indicating phase delay. Time of day is graphed in reference to the former light cycle (zeitgeber time, lights on during ZT 0-12). Therefore, if pubertal animals have a delay in the phase of the circadian pacemaker, then the phase of the PRC would also be delayed in these models. Model a: An elongation of $\tau$ during puberty would cause the circadian pacemaker and its rhythmic output to phase delay relative to the light cycle. The delay would provide more light exposure at a phase when the pacemaker is sensitive to advancing phase shift and thus allow entrainment (because $\tau-24 \mathrm{~h}=\Phi$, with $\Phi$ representing the magnitude of necessary daily phase resetting). Model $\mathbf{b}$ : An increase in the circadian pacemaker's relative sensitivity to the phase-delaying effects of light would also cause the pacemaker to delay relative to the light cycle. This delay would result because the pacemaker would need more light exposure at a phase when it is sensitive to advancing phase shift. 


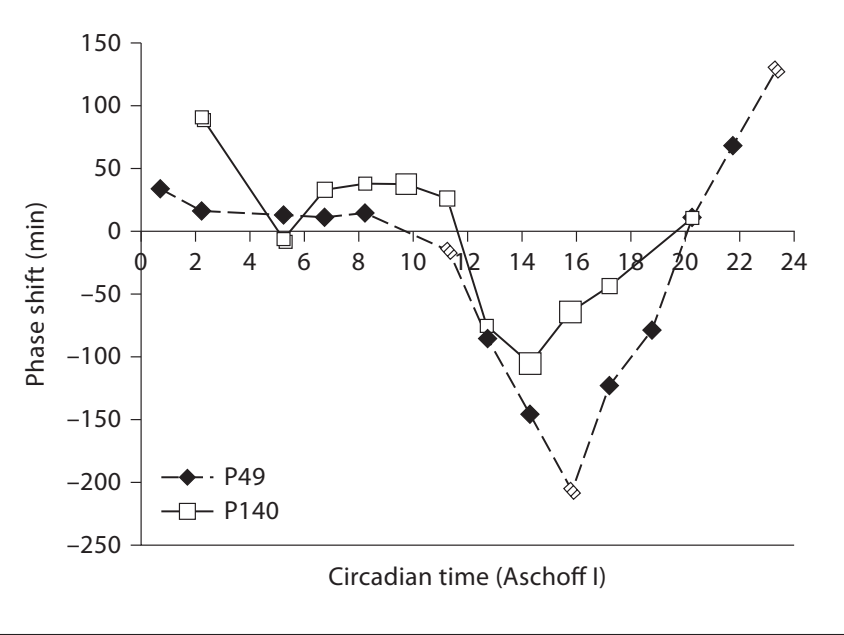

Fig. 2. Pubertal mice exhibit an exaggerated delay in circadian phase in response to evening light. Female mice were placed into constant darkness (DD) for two weeks and then exposed to a 15 min light pulse $(150 \mathrm{~lx})$. Circadian phase shift in response to the pulse was calculated in reference to sham (no pulse) conditions, and circadian time was defined in reference to the activity rhythms of the individual mice (activity onset $=$ CT12). Therefore, unlike figure 1, if pubertal animals have a delay in the phase of the circadian pacemaker, the phase of the PRC would not be delayed in this figure. The dotted line represents the phase response of mice that were likely to be pubertal at the time of the light-pulse (P49, $\mathrm{n}=34$ ) and the dark line represents the phase response of adults (P140, $n=34)$. Each point represents the average phase shift produced by light presented during a 1.5-hour bin. The sample size for each bin is represented by the size of the data point $(n=1-8)$. Adapted from Weinert and Kompauerova [52].

ity to the phase-delaying effects of light would also cause the pacemaker to delay relative to the light cycle (fig. 1, model B) [39]. To provide a preliminary test for this hypothesis, the suppression of melatonin secretion by 1hour light pulses was examined in early pubertal and late pubertal human adolescents. The photic suppression of melatonin secretion is mediated by the same pathways in the SCN as the discrete resetting of circadian rhythms [50]. Late adolescents were significantly less sensitive to dim light exposure $(15 \mathrm{~lx})$ in the morning (03:0004:00 h) than early adolescents, suggesting that a change in the shape of the PRC may have occurred during puberty [50]. Furthermore, adolescent humans (ages 15-17 years) still showed a phase delay of endocrine rhythms (dim light melatonin onset phase) on a weekend schedule that provided bright morning light exposure [51]. These studies suggest that pubertal humans may have a blunted phase advance response to light exposure in the morning and an exaggerated phase-delay response to light exposure in the evening.

In the animal literature, one previous study characterized the PRC of pubertal female mice (49 days of age), late pubertal (63 days of age) and adult mice [52]. When we compare the data of 49-day-old (P49) pubertal mice to the older animals (fig. 2), an interesting trend emerges. The phase-delay portion of the PRC has greater amplitude in the $\mathrm{P} 49$ pubertal mice. The phase advance and daytime portions of the PRC also appear to have a different shape, but it is difficult to draw conclusions due to the few sample points from these times. An earlier study showed that pubertal mice (42 days of age) adjust to a phase delay of the light-dark cycle much faster than adult mice [18]. These results suggest that pubertal animals may be relatively more sensitive to the circadian phase-delaying properties of light.

Entrainment of the Circadian Pacemaker Is Not the Only Determinant of the Final Phase of Circadian Output. Substantial evidence now indicates that adult diurnal and nocturnal species have a similar phasing of many aspects of SCN physiology $[53,54]$. For example, the phase of the transcriptional-translational clock gene feedback loop in the SCN that generates $24 \mathrm{~h}$ of oscillation is very similar in the nocturnal rat and diurnal degu [55]. The phasing of clock gene expression relative to the environmental light cycle is thought to reflect the entrainment of the circadian pacemaker [56]. Rhythms in deoxyglucose metabolism, photic sensitivity, and neuropeptide expression (e.g. AVP and VIP) in the SCN are also similar in diurnal and nocturnal species [53,54]. Therefore, the downstream coupling (or phase relationship) between the circadian pacemaker and central or peripheral systems plays an important role in determining the phase of behavioral and endocrine rhythms. To determine whether the delay in circadian phase during puberty is caused by a change in the phase of the circadian pacemaker in the SCN, the Lee laboratory has begun to characterize the phasing of the clock gene expression in the SCN of pubertal degus and rats.

\section{The Developmental Changes Driving Adolescent Sleep Patterns}

A number of studies provide strong support that the homeostatic and circadian regulation of sleep are sensitive to gonadal hormones. As this evidence has been extensively reviewed elsewhere [57-60], we only briefly summarize it here. Activational (direct, transient) effects 
of gonadal hormones on the sleep homeostasis and circadian systems are observed during natural gonadal hormone fluctuation in females $[26,60]$. Similarly, gonadectomy and the administration of estrogen, testosterone, progesterone, or neuroactive steroid metabolites in rodents produces immediate effects on the circadian properties and sleep architecture of adult males and females [57-59, 61, 62]. Organizational (long-term, permanent) effects occur in many species as well. Gonadal hormones can produce permanent sexual differentiation of circadian parameters (e.g. period) or differentiate these parameters' sensitivity to the activational effects of future hormones [61]. Some of the effects of gonadal hormones on circadian rhythms are due to modulation of the circadian pacemaker in the SCN. Gonadal hormones can alter key aspects of SCN physiology, including those necessary for the circadian rhythm generation, entrainment, and coupling $[57,63,64]$.

Little work has examined pubertal hormone effects, but there are indications of anatomical changes (growth in nuclear size and nucleoli size) in the SCN around midpuberty in rats [65-67]. Recently, the pre-pubertal gonadectomy of degus was found to block circadian phase changes around the time of puberty $[13,16]$. This evidence suggests that gonadal hormones are necessary for the development of delayed phase during adolescence. In contrast, an experiment in rats clearly showed gonadectomized individuals with a phase delay during puberty. However, the delay was smaller than that found in intact rats, suggesting that pubertal gonadal hormones in this species likely play a partial role in producing developmental changes in circadian phase [16]. Therefore, until additional studies are performed the data remain equivocal about the role of gonadal hormones in adolescent sleep patterns.

\section{Overall Summary and Relevance}

Adolescent changes in the timing of sleep reflect a developing circadian and homeostatic system. These changes are common across cultures and mammalian species and appear to be sexually differentiated in magnitude and timing. Our work indicates that teenagers have a slower accumulation of sleep drive in response to sleep deprivation, as well as an internal clock that interprets environmental time cues differently from adults.

These results have several important implications. First, the circadian mechanism cannot be assumed to be static after prenatal/infantile development. Our evidence suggests that a number of components of the circadian system change during puberty, including free-running period, continuous and discrete entrainment mechanisms, and recovery from photic phase shift. On a practical level, this means that circadian studies performed with college students may not generalize to the rest of the population.

For clinicians, these results emphasize the need for differential diagnostic considerations when treating sleep and circadian disorders in adolescents. This appears especially important for the diagnosis of circadian phase disorders, such as delayed or advanced sleep-phase disorders, as well as for insomnia and narcolepsy [4, 28, 68]. We also caution that interpretations of teenagers' complaints of malaise, fatigue and sadness need to take into account developmental sleep and circadian issues that are exacerbated by life in the 21st century [69].

For policy makers, teachers and parents, these results provide a clear mandate. The effects of sleep deprivation on grades, car accident risk, and mood are indisputable [70-72]. A number of school districts have moved middle and high school start times later with the goal of decreasing teenage sleep deprivation [73]. We support this approach, as results indicate that later school start times lead to decreased truancy and drop-out rates [73]. We can also help teenagers gain control over their own sleep patterns by teaching sleep and circadian principles in middle and high school health education. Minimizing exposure to light at night, as well as reducing computer or TV usage immediately before bedtime can naturally advance circadian phase. Similarly, incorporating outdoor morning activity into a teenage schedule can reduce trouble falling asleep at night [74].

\section{Acknowledgements}

We would like to thank Dr. Megan Mahoney, David Altshuler, Meghan Hewlett, Andrea King, Shouqi Scott Wang, HeeYoung $\mathrm{Ku}$, and Matthew Taylor for their feedback on this manuscript and Christine Acebo, Stephanie Crowley, Oskar Jenni, and Ron Seifer for technical support. This research was supported by the National Science Foundation (TML, MHH, JIP - IBN-0212322), the National Heart, Lung, and Blood Institute (MHH - T32 HD07048), and the National Institutes of Health (MAC MH45945, NR04279, MH52415, MH01358, and MH076969). 


\section{References}

1 National Sleep Foundation Sleep and Teens Task Force: Adolescent Sleep Needs and Patterns: Research Report and Resource Guide. Washington, National Sleep Foundation, 2000, pp 1-26.

$\checkmark 2$ Yang CK, Kim JK, Patel SR, Lee JH: Age-related changes in sleep/wake patterns among Korean teenagers. Pediatrics 2005;115(1 suppl):250-256.

-3 Thorleifsdottir B, Bjornsson JK, Benediktsdottir B, Gislason TH, Kristbjarnarson H: Sleep and sleep habits from childhood to young adulthood over a 10 -year period. J Psychosom Res 2002;53:529-537.

-4 Crowley SJ, Acebo C, Carskadon MA: Sleep, circadian rhythms, and delayed phase in adolescence. Sleep Med 2007;8:602-612.

5 Roenneberg T, Kuehnle T, Pramstaller PP, Ricken J, Havel M, Guth A, Merrow M: A marker for the end of adolescence. Curr Biol 2004;14:R1038-R1039.

-6 Russo PM, Bruni O, Lucidi F, Ferri R, Violani C: Sleep habits and circadian preference in Italian children and adolescents. J Sleep Res 2007;16:163-169.

7 Carskadon MA, Acebo C, Jenni OG: Regulation of adolescent sleep: implications for behavior. Ann NY Acad Sci 2004;1021:276291.

8 Carskadon MA: Maturation of processes regulating sleep in adolescents; in Marcus CL, Carroll JL, Donnelly DF, Loughlin GM (eds): Sleep in Children: Developmental Changes in Sleep Patterns, ed 2. Informa Healthcare, 2008, pp 95-109.

-9 Crowley SJ, Acebo C, Fallone G, Carskadon MA: Estimating dim light melatonin onset (DLMO) phase in adolescents using summer or school-year sleep-wake schedules. Sleep 2006;29:1632-1641.

10 Carskadon MA, Acebo C, Richardson GS, Tate BA, Seifer R: An approach to studying circadian rhythms in adolescents. J Biol Rhythms 1997;12:278-289.

11 Carskadon MA, Vieira C, Acebo C: Association between puberty and delayed phase preference. Sleep 1993;16:258-262.

12 Golub MS, Takeuchi PT, Hoban-Higgins TM: Nutrition and circadian activity offset in adolescent rhesus monkeys; in Carskadon MA (ed): Adolescent Sleep Patterns: Biological, Social, and Psychological Influences. Cambridge, Cambridge University Press, 2002, pp 50-68.

13 Hummer DL, Jechura TJ, Mahoney MM, Lee TM: Gonadal hormone effects on entrained and free-running rhythms in the developing diurnal rodent, Octodon degus. Am J Physiol Regul Integr Comp Physiol 2007;292:R586R597.
14 Tate BA, Richardson GS, Carskadon MA: Maturational changes in sleep-wake timing: longitudinal studies of circadian activity rhythm of a diurnal rodent; in Carkadon MA (ed): Adolescent Sleep Patterns: Biological, Social, and Psychological Influences. Cambridge, Cambridge University Press, 2002, pp 40-49.

15 Perryman JI, Crowley SJ, Opp MR, Lee TM: Sleep responses to 6-h deprivation in male juvenile Octodon degus. Society for Research on Biological Rhythms Meeting Abstracts. Sandestin, Society for Research on Biological Rhythms Conference, 2008, pp 240-241. http://www.srbr.org/Documents/SRBR_ 2008_Program.pdf.

16 Hagenauer MH, Ku HY, King AF, Dimitrov M, Lee TM: 'It's just a phase': Delays in circadian phase during puberty in the nocturnal rat and diurnal Octodon degus. Society for Research on Biological Rhythms Meeting Abstracts. Sandestin, Society for Research on Biological Rhythms Conference, 2008, p 207. http://www.srbr.org/Documents/ SRBR_2008_Program.pdf.

17 McGinnis MY, Lumia AR, Tetel MJ, Molenda-Figueira HA, Possidente B: Effects of anabolic androgenic steroids on the development and expression of running wheel activity and circadian rhythms in male rats. Physiol Behav 2007;92:1010-1018.

18 Weinert D, Eimert H, Erkert HG, Schneyer $\mathrm{U}$ : Resynchronization of the circadian corticosterone rhythm after a light/dark shift in juvenile and adult mice. Chronobiol Int 1994;11:222-231.

19 Weinert D, Waterhouse J: Daily activity and temperature rhythms do not change spontaneously with age in laboratory mice. Physiol Behav 1999;66:605-612.

20 Neuman A, Gothilf Y, Haim A, Ben-Aharon G, Zisapel N: Nocturnal patterns and upregulated excretion of the melatonin metabolite 6-sulfatoxymelatonin in the diurnal rodent Psammomys obesus post-weaning under a short photoperiod. Comp Biochem Physiol [A] 2005;142:297-307.

21 Plant TM: Puberty in primates; in Knobil E, Neill JD (eds): Physiol Reprod. Raven Press, 1994, pp 453-485.

22 Ojeda SR, Urbanski HF: Puberty in the rat; in Knobil E, Neill JD (eds): Physiol Reprod. New York, Raven Press, 1994, pp 363-409.

-23 Nelson JF, Karelus K, Felicio LS, Johnson TE: Genetic influences on the timing of puberty in mice. Biol Reprod 1990;42:649-655.

24 Safranski TJ, Lamberson WR, Keisler DH: Correlations among three measures of puberty in mice and relationships with estradiol concentration and ovulation. Biol Reprod 1993;48:669-673.
-25 Windmill K, Tenne-Brown J, Bayles R, Trevaskis J, Gao Y, Walder K, Collier GR: Localization and expression of selenoprotein $\mathrm{S}$ in the testis of Psammomys obesus. J Mol Hist 2007;38:97-101.

26 Albers HE, Gerall AA, Axelson JF: Effect of reproductive state on circadian periodicity in the rat. Physiol Behav 1981;26:21-25.

27 Taylor DJ, Jenni OG, Acebo C, Carskadon MA: Sleep tendency during extended wakefulness: insights into adolescent sleep regulation and behavior. J Sleep Res 2005; 14:239244.

28 Carskadon MA, Harvey K, Duke P, Anders TF, Litt IF, Dement WC: Pubertal changes in daytime sleepiness. Sleep 1980;2:453-460.

29 Kohyama J: A newly proposed disease condition produced by light exposure during night: asynchronization. Brain Dev 2008; [epub ahead of print].

30 Giedd JN, Blumenthal J, Jeffries NO, Castellanos FX, Liu H, Zijdenbos A, Paus T, Evans AC, Rapoport JL: Brain development during childhood and adolescence: a longitudinal MRI study. Nat Neurosci 1999;2:861-863.

31 Gunduz G, Stetson MH: Effects of photoperiod, pinealectomy, and melatonin implants on testicular development in juvenile Siberian hamsters (Phodopus sungorus). Biol Reprod 1994;51:1181-1187.

32 Achermann P, Borbély AA: Mathematical models of sleep regulation. Front Biosci 2003;8:S683-S693.

33 Jenni OG, Van Reen E, Carskadon MA: Regional differences of the sleep electroencephalogram in adolescents. J Sleep Res 2005; 14:141-147.

- 34 Jenni OG, Achermann P, Carskadon MA: Homeostatic sleep regulation in adolescents. Sleep 2005;28:1446-1454.

35 Alfoldi P, Tobler I, Borbely AA: Sleep regulation in rats in early development. Am J Physiol 1990;258:R634-R644.

36 Trachsel L, Tobler I, Borbely AA: Sleep regulation in rats: effects of sleep deprivation, light, and circadian phase. Am J Physiol1986; 251:R1037-R1044.

37 Tobler I, Borbely AA: The effect of 3-h and 6-h sleep deprivation on sleep and EEG spectra of the rat. Behav Brain Res 1990;36:7378.

38 Ralph MR, Foster RG, Davis FC, Menaker M: Transplanted suprachiasmatic nucleus determines circadian period. Science 1990;247: 975-978.

-39 Roenneberg T, Daan S, Merrow M: The art of entrainment. J Biol Rhythms 2003;18:183194.

40 Moore-Ede MC, Sulzman FM, Fuller CA: Clocks That Time Us: Characteristics of Circadian Clocks. Cambridge, Harvard University Press, 1982, pp 30-112. 
41 Hut RA, van Oort BE, Daan S: Natural entrainment without dawn and dusk: the case of the European ground squirrel. J Biol Rhythms 1999;14:290-299.

42 Pittendrigh CS, Daan S: Functional analysis of circadian pacemakers in nocturnal rodents. I. The stability and lability of spontaneous frequency. J Comp Physiol 1976;106: 223-252.

43 Hagenauer MH, Hummer DL, Agrusa JA, Cost KA, Sutton BC, Lee TM: Sensitivity of the circadian clock to light changes during puberty in the nocturnal rat and the diurnal Octodon degus. Society for Neuroscience Meeting Abstracts. San Diego, Society for Neuroscience, 2007. http://www.sfn.org/ am2007/index.cfm?pagename=call_for_abstracts

44 Carskadon MA, Labyak SE, Acebo C, Seifer $\mathrm{R}$ : Intrinsic circadian period of adolescent humans measured in conditions of forced desynchrony. Neurosci Lett 1999;260:129132.

45 Lee TM, Labyak SE: Free-running rhythms and light- and dark-pulse phase response curves for diurnal Octodon degus (Rodentia). Am J Physiol 1997;273:R278-R286.

46 Martinez JL: Effects of selected illumination levels on circadian periodicity in the rhesus monkey, Macaca mulatta. J Interdiscipl Cycle Res 1972;3:47-59.

47 Summer TL, Ferraro JS, McCormack CE: Phase response and Aschoff illuminance curves for locomotor activity rhythm of the rat. Am J Physiol Regul Integr Comp Physiol 1984;246:299-304

48 Tokura H, Aschoff J (eds): Circadian activity rhythms of the pig-tailed macaque, Macaca nemestrina, under constant illumination (in German). Pflügers Arch 1978;376:241-243.

49 Daan S, Pittendrigh CS: Functional analysis of circadian pacemakers in nocturnal rodents. III. Heavy water and constant light: homeostasis of frequency? J Comp Physiol 1976;106:267-290.

-50 Carskadon MA, Acebo C, Arnedt JT: Failure to identify pubertally-mediated melatonin sensitivity to light in adolescents. Sleep 2002; 25:A191.

51 Crowley SJ: Weekend recovery sleep in adolescents: can it occur without a circadian phase delay? Dissertation submitted in partial fulfillment of the requirements for the degree of doctor of philosophy in the department of psychology of Brown University, 2009.
52 Weinert D, Kompauerova V: Light induced phase and period responses of circadian activity rhythms in laboratory mice of different age. Zoology 1998;101:45-52.

53 Smale L, Lee T, Nunez AA: Mammalian diurnality: some facts and gaps. J Biol Rhythms 2003;18:356-366.

54 Hagenauer MH, Lee TM: Circadian organization of the diurnal Caviomorph rodent, Octodon degus. Biol Rhythm Res 2008;39: 269-289.

55 Vosko AM, Hagenauer MH, Hummer TL, Lee TM: Period gene expression in the diurnal degu (Octodon degus) differs from the nocturnal laboratory rat (Rattus norvegicus). Am J Physiol Regul Integr Comp Physiol 2009;296:R353-R361.

56 Shigeyoshi Y, Taguchi K, Yamamoto S, Takekida S, Yan L, Tei H, Moriya T, Shibata S, Loros JJ, Dunlap JC, Okamura H: Lightinduced resetting of a mammalian circadian clock is associated with rapid induction of the mPerl transcript. Cell 1997;91:10431053.

57 Karatsoreos IN, Silver R: Minireview: the neuroendocrinology of the suprachiasmatic nucleus as a conductor of body time in mammals. Endocrinology 2007;148:5640-5647.

58 Manber R, Armitage R: Sex, steroids, and sleep: a review. Sleep 1999;22:540-555.

59 Leibenluft E: Do gonadal steroids regulate circadian rhythms in humans? J Affect Disord 1993;29:175-181.

60 Baker FC, Driver HS: Circadian rhythms, sleep, and the menstrual cycle. Sleep Med 2007;8:613-622.

61 Albers HE: Gonadal hormones organize and modulate the circadian system of the rat. Am J Physiol 1981;241:R62-R66.

62 Pinto FT, Golombek DA: Neuroactive steroids alter the circadian system of the Syrian hamster in a phase-dependent manner. Life Sci 1999;65:2497-2504.

63 Nakamura TJ, Moriya T, Inoue S, Shimazoe T, Watanabe S, Ebihara S, Shinohara K: Estrogen differentially regulates expression of Perl and Per2 genes between central and peripheral clocks and between reproductive and nonreproductive tissues in female rats. J Neurosci Res 2005;82:622-630.

64 Shinohara K, Funabashi T, Nakamura TJ, Kimura F: Effects of estrogen and progesterone on the expression of connexin-36 mRNA in the suprachiasmatic nucleus of female rats. Neurosci Lett 2001;309:37-40.
65 Morishita H, Nagamachi N, Kawamoto M, Tomioka M, Higuchi K, Hashimoto T, Tanaka T, Kuroiwa S, Nakago K, Mitani H, Miyauchi Y, Ozasa T, Adachi H: The effects of prepuberal castration on the development of the nuclear sizes of the neurons in the hypothalamic nuclei of female rats. Brain Res 1978;146:388-391.

66 Morishita H, Kawamoto M, Masuda Y, Higuchi K, Tomioka M, Nagamachi N, Mitani H, Ozasa T, Adachi H: Quantitative histological changes in the hypothalamic nuclei in the prepuberal, puberal, and postpuberal female rat. Brain Research 1974;76:41-47.

67 Anderson CH: Nucleolus: changes at puberty in neurons of the suprachiasmatic nucleus and the preoptic area. Exp Neurol 1981;74: 780-786.

68 Carskadon MA, Wolfson AR, Acebo C, Tzischinsky O, Seifer R: Adolescent sleep patterns, circadian timing, and sleepiness at a transition to early school days. Sleep 1998; 21:871-881.

69 Carskadon MA: Sleep difficulties in young people. Arch Pediatr Adolesc Med 2004;158: 597-598.

70 Carskadon MA: Risks of driving while sleepy in adolescents and young adults; in Carskadon MA (ed): Adolescent Sleep Patterns: Biological, Social, and Psychological Influences. Cambridge, Cambridge University Press, 2002, pp 148-158.

71 Wolfson AR, Carskadon MA: Sleep schedules and daytime functioning in adolescents. Child Dev 1998;69:875-887.

72 Wolfson AR, Carskadon MA: Understanding adolescent sleep patterns and school performance: a critical appraisal. Sleep Med Rev 2003;7:491-506.

73 Wahlstrom KL: Accommodating the sleep patterns of adolescents within current educational structures: an uncharted path; in Carskadon MA (ed): Adolescent Sleep Patterns: Biological, Social, and Psychological Influences. Cambridge, Cambridge University Press, 2002, pp 172-197.

74 Harada T, Morisane H, Takeuchi H: Effect of daytime light conditions on sleep habits and morningness-eveningness preference of Japanese students aged $12-15$ years. Psychiatry Clin Neurosci 2002;56:225-226. 